\title{
Kimyasal Mordanların Varlığında Nylon Kumaşların Reaktif Boyarmaddelerle Boyanmasının Araştırılması
}

\author{
Güzin Akyol ${ }^{1,2}$, Behçet Becerir ${ }^{3 *}$ \\ ${ }^{1}$ Bursa Uludağ Üniversitesi, Fen Bilimleri Enstitüsü, Tekstil Mühendisliği Anabilim Dal, Bursa, Türkiye, (ORCID: 0000-0001-8229-4249), guznakyl@gmail.com \\ ${ }^{2}$ Bursalı Tekstil San. ve Tic. A.S., Demirtaş Organize Sanayi Bölgesi, 16369, Bursa, Türkiye \\ 3* Bursa Uludağ Üniversitesi, Mühendislik Fakültesi, Tekstil Mühendisliği Bölümü, Bursa, Türkiye (ORCID: 0000-0002-2655-2773), *becerir@uludag.edu.tr
}

(1st International Conference on Applied Engineering and Natural Sciences ICAENS 2021, November 1-3, 2021)

(DOI: 10.31590/ejosat.1021550)

\begin{abstract}
ATIF/REFERENCE: Akyol, G. \& Becerir, B. (2021). Kimyasal Mordanların Varlığında Nylon Kumaşların Reaktif Boyarmaddelerle Boyanmasının Araştırılması. Avrupa Bilim ve Teknoloji Dergisi, (28), 1476-1485.

$\ddot{\mathrm{O} z}$

Nylon lifleri endüstriyel olarak üretilen sentetik liflerin ilk üyesi olup, görünüm ve dayanım özellikleri sayesinde poliester ve akrilik ile beraber en fazla kullanılan sentetik liflerden birisidir. Reaktif boyarmaddeler 1950’leri ortalarında piyasaya sürülmüş ve selülozik liflerin boyanmasında en fazla kullanılan boyarmaddelerdir. Reaktif boyarmaddelerin en büyük özelliği liflerdeki uygun gruplar ile kovalent bă̆ yapma yapabilmeleridir. Mordan kullanımı özellikle doğal boyarmadde uygulamalarında gerekli olup, boyarmaddelerin lif içinde tutunma ve kalma özelliklerini iyileştirirler. Bu çalışmada nylon kumaşların reaktif boyarmaddelerle boyanmasında mordan kimyasallarının kullanımı araştırılmış olup, uygulanan boyama şartları altında daha iyi boyarmadde çekimi ve renklendirme özelliklerinin eldesi incelenmiştir. Çalışmada reaktif grup olarak Trifloropirimidin (TFP) fonksiyonel grubuna sahip mavi renkte boyarmadde kullanılmıştır. Belirlenen üç farklı proses, $\mathrm{pH}$ ve mordan türünde çalışmalar yapılmıştır. Boyama öncesi ve sonrası boyama çözeltilerinden alınan sıvı numunelerinin spektrofotometrede transmitans/absorbans ölçümleri yapılarak, yüzde boyarmadde çekimleri değerlendirilmiştir. Uygulanan üç farklı proses sonunda nylon kumaşların mordanlı ve mordansız boyama sonrasında renk ölçümleri yapılmıştır. Elde edilen sonuçlar mordan varlı̆̆ında nylon liflerinin reaktif boyarmaddelerle boyanma özelliklerinin ön mordanlama ve eş zamanlı mordanlama yöntemleri ile geliştirilebileceğini göstermiştir.
\end{abstract}

\section{Investigation of Reactive Dyeing of Nylon Fabrics in the Presence of Chemical Mordants}

\begin{abstract}
Nylon fibres are the first synthetic fibres to be produced in industrial scale and they are one of the most consumed synthetic fibres besides polyester and acrylic due to their visual and usage properties. Reactive dyes were commercially produced in mid-20th century and they are mostly preferred in dyeing of cellulosic fibres. The most important property of reactive dyes is their ability to make covalent bonds within the fibre. Mordants are used mainly in the application of natural dyes to hold and retain the dye molecules in the fibre. In this paper, nylon fabrics were dyed with a reactive dye with trifluoropyrimidine (TFP) functional group having a blue hue in the presence of chemical mordants to obtain better exhaustion and coloration properties. Dyeings were performed with three different dyeing/mordanting methods at three $\mathrm{pH}$ levels. Three chemical mordans were used. Dye exhaustion percentages were determined by transmittance/absorbance measurements of dyeing liquors prior and after dyeing. The reflectance measurements of the dyed fabric samples were recorded and colour strength values were obtained. The results revealed that mordant usage with pre-mordanting and meta-mordanting methods improved the coloration properties of reactive dyes on nylon fabrics.
\end{abstract}




\section{Giriş}

Poliamid lifleri ticari kullanımda çoğunlukla 'nylon' ticari ismiyle bilinirler ve genel olarak nylon kelimesi poliamid liflerini ifade etmek için kullanılır. Özel amaçlar için üretilen yüksek performanslı poliamid lifleri (aromatik poliamidler) (Kevlar, Nomex vb.) benzer şekilde ticari isimleriyle bilinirler (Burkinshaw, 1995).

Nylon 6,6 lifleri poli-hekzametilen-adipat poliamid polimerinden polikondenzasyon reaksiyonu ile elde edilirler. Tekstilin yanı sıra diğer endüstriyel alanlarda da büyük ve önemli kullanıma sahip olan nylon lifleri parlaklık, mukavemet, dayanıklılık, kimyasallara karşı direnç ve kısmi hidrofobluk özellikleriyle ön plana çıkarlar (Burkinshaw, 1995; Lewis ve MacDoughall, 1998).

Tekstil ve hazır giyim üretiminde renkli olarak kullanılmak istenen nylon liflerinin daha koyu renklerde ve daha yüksek yaş haslıklarda boyanması konusunda her zaman talepler vardır. Bu taleplerin karşılanmasına yönelik olarak nylon liflerinin reaktif boyarmaddelerle renklendirilmesi ve elde edilen renklerin ve yaş haslıkların geliştirilmesi konusu üzerinde uzun yıllardır çalışılmaktadır. Bu çalışmalar özellikle boyama pH'ı, kullanılan boyarmaddenin çözünürlük sağlayan grupları ve kovalent bağ yapan reaktif grupları üzerinden yapılmıştır (Burkinshaw ve Ganghi. 1996, 1997a, 1997b).

Reaktif boyarmaddeler 1956 y1lında ve ilk örnekleri İngiliz ICI firması tarafından selülozik mamullerin boyanmasına yönelik olarak piyasaya sürülmüş olan boyalardır. Reaktif boyarmaddeler öncelikle çözelti içindeki asit-alkali şartlar altındaki davranışları iyi bilinen yün liflerinin boyanması için araştırılmış olup, sentezlenen boya ve reaktif grupların alkali şartlar altında selülozik lifleri çok iyi renklendirmelerinin bulunmasıyla selülozik liflerin boyanmasına yönelik olarak kullanılmaya başlanmıştır (Rys ve Zollinger, 1989). Bu boyarmaddeler günümüzde poliester liflerinin boyanmasında kullanılan dispers boyarmaddeler ile beraber en yüksek üretim ve tüketime sahip boyalardır. Reaktif boyarmaddeler selülozik liflerle özellikle alkali şartlar altında reaksiyon verme kabiliyetine sahip anyonik fonksiyonel gruplu boyalar olup, belli şartlar altında sentezlenmiş bazı yap1 ve özel gruplar asidik şartlar altında yün liflerini de renklendirme kabiliyetine sahiptir. Reaktif boyarmaddeler renklendirme ve bağ yapma özellikleri nedeniyle belli şartlar altında nylon liflerini de boyama kabiliyetine sahiptir (Sumithra ve Arasi, 2014). Nylon lifleri belli $\mathrm{pH}$ şartları altında reaktif boyarmaddelerin çözünürlük sağlayan sülfonik asit grupları ve reaktif grupları ile reaksiyon verebilir. Bununla birlikte her zaman koyu renklerde ve yüksek yaş haslıklara sahip boyamalar yapılamaz.

Lewis ve MacDangall boyama şartları altında lif içinde terminal amino gruplarının sadece bir kısmının kovalent bağ reaksiyonu verebildiğini bunun lif kristalinitesi ve lif iç negatif yükü ile ilişkili olduğu sonucuna varmışlardır (Lewis ve MacDangall, 1998). Burkinshaw ve Ganghi konvansiyonel ve mikrolif nylon kumaşların farklı reaktif boyarmaddelerle boyanması konusunda çalışmışlardır Düşük boyarmadde konsantrasyonlarında benzer renk derinliğinde boyamalar elde ederken, boyarmadde konsantrasyonu arttıkça konvansiyonel liflerden mamul kumaşların renk derinliklerinin daha fazla arttığ sonucuna ulaşmışlardır (Burkinshaw ve Ganghi (1996, 1997a ve 1997b). Sumithra ve Arasi (2014) seçilen belli boyama şartları altında reaktif ve asit boyarmaddelerin nylon 6,6, kumaşlarda benzer renklendirme özellikleri verdiğin belirtmişlerdir. Soleimani-Gorgani ve Taylor (2006a, 2006b ve 2008) farkl1 moleküler özelliklere sahip reaktif boyarmaddelerle yaptıkları çalışmalarda, çalışma için kullandıkları reaktif boyarmaddeleri nylon lifleri ile olan fiksasyon işlemlerinde molekül şekli ve tipinin daha önemli olduğu ve reaktif grup sayının fiksasyon üzerinde daha az etkili olduğunu ifade etmişlerdir.

Burkinshaw ve ark. (2001) çözelti pH değişimine bağlı olarak heterobifonksiyonel reaktif boyarmaddelerin nylon 6,6 kumaşlarda verdikleri çekim miktarlarını araştırmışlar ve sonuçları uygulama pH'ı ile ilişkilendirmişlerdir. El-Gabry ve ElZawary (2008) mordan olarak Tannik Asit kullanımı ile nylon 6 kumaşların bir katyonik boyarmadde ile emülsiyon şartları boyanmasını araştırmışlar ve bu uygulamanın sulu şartlar altında boyamaya göre daha iyi haslık özellikleri verdiğini belirtmişlerdir.

Araştırma literatüründe nylon 6,6 kumaşların reaktif boyarmaddelerle boyanmasında mordan kullanımı konusunda temel olabilecek çalışmalar bulunmamaktadır. Yapılan deneysel çalışmalar genel olarak boyarmadde moleküler özellikleri ve boyama parametrelerinin optimizasyonu yönünde yapılmıştır.

$\mathrm{Bu}$ araştırmada sunulan deneysel çalışmada nylon 6,6 liflerinden mamul kumaş numunesi TFP reaktif gruba sahip reaktif boya ile doğal mordan kimyasalları varlığında boyanarak, lifler tarafından bağlanan boyarmadde molekül miktarının arttırılması ve daha yüksek renk derinliğine sahip daha koyu renklerin eldesi amaçlanmıştır.

\section{Materyal ve Metot}

\subsection{Materyal}

Çalışmada \%100 nylon 6,6 kumaş kullanılmıştır. Çözgü ipliği olarak 140/136 numara (denye/filament sayısı) nylon 6,6 kullanılmış ve çözgü sıklığı 49 çözgü/cm'dir. Atkı ipliği olarak 70/68 numara (denye/filament sayısı) nylon 6,6 kullanılmış ve atkı sıklığı $39 \mathrm{~cm} /$ atkıdır. Kumaş örgüsü Dimi 2/1 ve kumaş gramaj1 $176 \mathrm{~g} / \mathrm{m} 2$ 'dir.

Çalışmada Trifloropirimidin (TFP) fonksiyonel gruba sahip mavi reaktif boyarmadde kullanılmıştır. Boyamalar Ataç marka numune boyama makinesinde yapılmıştır. Boyama sonrası kumaş numuneleri 1lık su ile 10 dakika durulanmıştır.

Boyama sonrası renk derinlikleri (K/S) ve boyama çözeltisi absorbans değerleri Datacolor 800 L reflektans (ve transmitans) spektrofotometrede ölçülmüştür.

$\mathrm{Bu}$ çalışmada mordan olarak Potasyum Aluminyum Sülfat (Alum), Demir (II) Sülfat ve Tannik Asit laboratuvar saflığında kullanılmıştır.

\subsection{Metot}

Boyama çalışmaları $\% 0,5, \% 1$ ve $\% 2$ olarak üç konsantrasyonda gerçekleştirilmiştir. Boyama çözeltisi $\mathrm{pH}$ seviyeleri $\mathrm{pH} 2$, $\mathrm{pH} 4$ ve $\mathrm{pH} 6$ olarak seçilmiş ve $\mathrm{pH}$ ayarı için Mcllvaine tampon çözeltisi kullanılmıştır. Boyamalar 1:20 flotte oranında yapılmış, maksimum boyama sıcaklığı olarak $102^{\circ} \mathrm{C}$ ve boyama süresi $60 \mathrm{dk}$ olarak seçilmiştir.

Uygulanan mordan miktarı \%0,1 olarak düşük bir konsantrasyonda seçilmiştir. Mordan uygulamaları tekstil boyama literatüründe geleneksel olarak bilinen üç yöntem ile yapılmıştır. 
Bunlar; ön mordanlama, eş zamanlı mordanlama, ve son mordanlamadir.

Boyama öncesi ve sonrasında çözelti absorbans değerlerinin ölçümü için $1 \mathrm{ml}$ numuneler alınarak $20 \mathrm{ml}$ 'ye seyreltilmiştir. Spektrofotometre cihazı ile alınan absorbans verileri kaydedilmiştir.

Bulgular kısmında verilen \% Boyarmadde Çekimi aşağıdaki şekilde hesaplanmıştır:

$\%$ Boyarmadde Çekimi $=[(\mathrm{A} 0-\mathrm{A} 1) / \mathrm{A} 0] \times 100$

burada;

A0 : Boyama Öncesi Çözelti Absorbansı

\section{A1 : Boyama Sonrası Çözelti Absorbansı}

Renk ölçüm sonucu ve değerlendirmesi Kubelka-Munk denklemine göre renk derinliği (Renk Kuvveti) olarak verilmiştir. Buna göre:

$\mathrm{K} / \mathrm{S}=(1-\mathrm{R} 2) / 2 \mathrm{R}$

burada;

$\mathrm{K}$ : Yüzeyin Işı̆̆ı Absorblama Katsayısı

\section{S : Yüzeyin Işı̆̆ı Saçma Katsayısı}

$\mathrm{R}: \lambda$ Dalga boyundaki Kısmi Reflektans ( $\square \max$ )

Absorbans/transmitans ve reflektans ölçümleri $610 \mathrm{~nm}$ maksimum absorbans dalga boyunda ( $\square$ max) gerçekleştirilmiş ve sonuçlar kaydedilmiştir.

\subsection{1. Ön Mordanlama Yöntemi İle Boyama}

Ön mordanlama yöntemine göre boyama prosesi Şekil 1'de verilmiştir. Boyama banyosunun $\mathrm{pH}^{\prime} 1$ hazırlanan Mcllvaine tampon çözeltisi ile boyama öncesinde numune tüplerine eklenerek ölçülen $\mathrm{pH}$ değerleri kaydedilmiştir. $80^{\circ} \mathrm{C}$ ' de yarım saat işlem gören mordanlı kumaşların tekrar $\mathrm{pH}$ değerleri ölçülerek bu aşamada reaktif boyarmadde eklenmiştir. Boyama öncesi absorbans değeri olarak boyarmadde ilavesinden sonra boya banyosundan transmitans ölçümleri yapılmıştır. Proses sonunda boyama sonrası $\mathrm{pH}$ değerleri ve absorbans değerleri aynı seyreltme oranında alınarak ölçülmüştür.

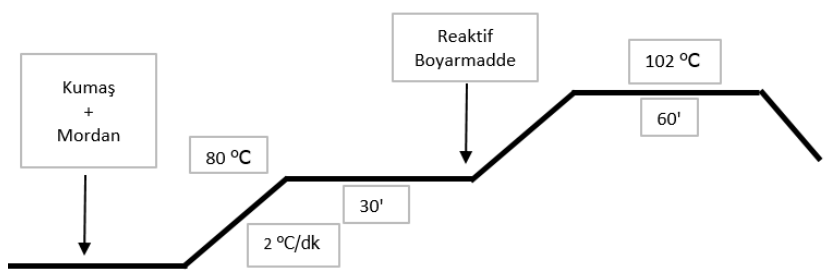

\section{Şekil 1. Ön Mordanlama Prosesi}

\subsubsection{Eş Zamanlı Mordanlama Yöntemi İle Boyama}

Şekil 2'de verilen eş zamanlı mordanlama yöntemde boyarmadde ve mordan kimyasalı boyama başlangıcında beraber çözeltiye ilave edilmiştir. Her bir numune tüp içinde boyama öncesi $\mathrm{pH}$ değerleri alınarak boyama sonrasındaki $\mathrm{pH}$ değişimleri ile karşılaştırılmıştır.

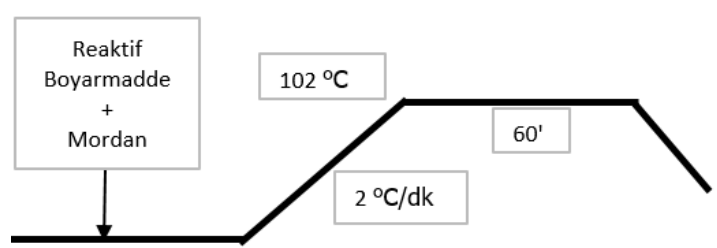

\section{Şekil 2. Eş Zamanlı Mordanlama}

\subsubsection{Son Mordanlama Yöntemi İle Boyama}

Son mordanlama yöntemine göre boyama için Şekil 3'teki proses kullanılmıştır. Hazırlanan Mcllvaine tampon çözeltisi reaktif boyarmadde ilave edilerek boyama öncesinde $1 \mathrm{ml}$ alınıp $20 \mathrm{ml}$ 'ye seyreltilerek absorbans değerleri kaydedilmiştir. $80^{\circ} \mathrm{C}$ ' de yarım saat işlem gören kumaş boyama makinesinden çıkartılarak tekrar absorbans değerleri belirlenen oranda seyreltilerek ölçülmüştür. Nylon kumaş üzerinde ilk yarım saatlik sürede boyarmadde çekiminin analizi için yapılan bir uygulamadır. Her bir mordan, $\mathrm{pH}$ ve $\%$ boyarmadde için bu işlem tekrarlanmıştır. Mordan ilavesinin ardından boyama bitiminde kumaşların absorbans değerleri boyama sonrası olarak kaydedilmiştir.

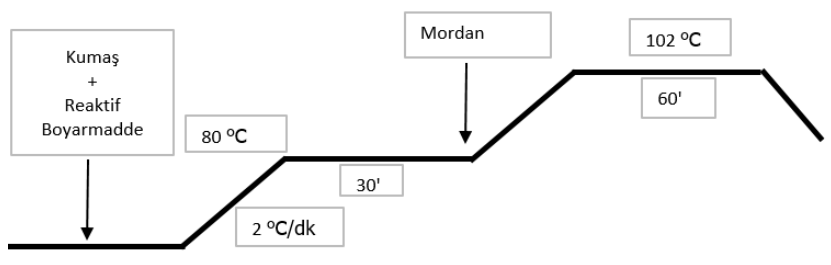

Şekil 3. Son Mordanlama Prosesi

Mordansız boyama için Şekil 2'de verilen boyama yöntemi başlangıçta mordan ilavesi yapılmadan kullanılmıştır. Bu yöntem aynı zamanda mordansız olarak nylon kumaşların reaktif boyarmaddelerle boyanmasında kullanılan temel boyama yöntemidir (Burkinshaw, 1995; Burkinshaw ve Gangi, 1996a, 1997b; Burkinshaw ve Bide, 2001)

\section{Araştırma Sonuçları ve Tartışma}

\subsection{Araştırma Sonuçları}

Nylon kumaşın trifloropirimidin (TFP) reaktif gruba sahip mavi reaktif boyarmadde ile mordan varlığında boyanması, belirtilen üç prosese göre gerçekleştirilmiştir. Boyama öncesi ve sonrası $\mathrm{pH}$ ölçümleri yapılmıştır.

Yapılan $\mathrm{pH}$ ölçümlerinde $\mathrm{pH}$ değerlerinin boyama sonuçlarını etkileyecek kadar sapma göstermediği ve minimum sayısal değişismlerin (yüzdelik basamakta 1-5 arası) ortaya çıktığ 1 tespit edilmiştir.

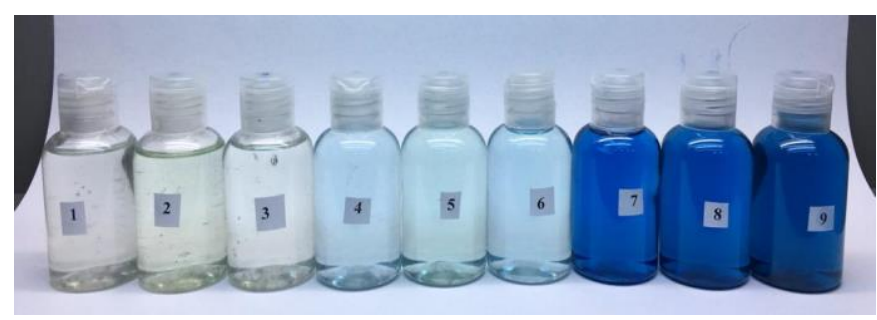


Şekil 4. \%0,5 TFP boya ile ön mordanlama prosesi sonu boyama çözeltileri

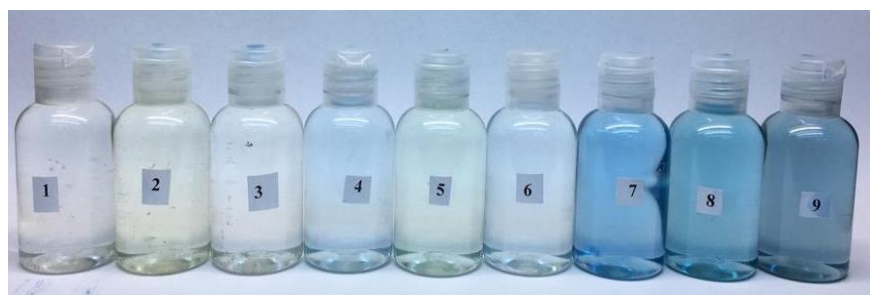

Şekil 5. \%0,5 TFP boya ile eş zamanlı mordanlama prosesi sonu boyama çözeltileri

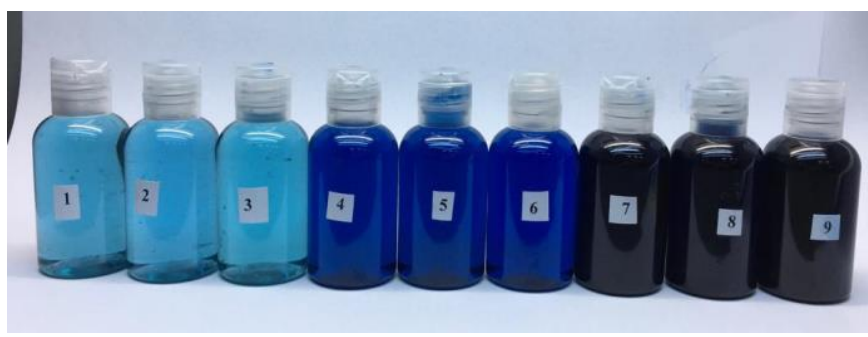

Şekil 6. \%0,5 TFP boya ile son mordanlama prosesi sonu boyama çözeltileri

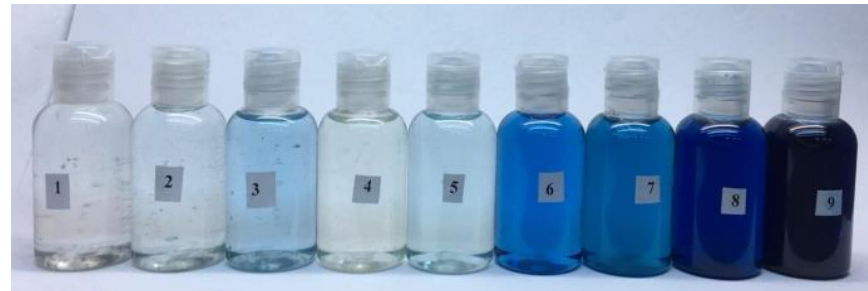

Şekil 7. \%0,5 TFP boya ile mordansız boyama prosesi sonu boyama çözeltileri

Boyama sonrası elde edilen çözeltilere örnek olarak \% 0,5 boyama konsantrasyonu için $\mathrm{pH} 2,4$ ve 6'da üç farklı proses ve mordan için çözeltilerin görselleri verilmiştir. \%0,5 TFP boyama ile ön mordanlama prosesi sonrası boyama banyosunun görseli Şekil 4'te verilmiştir. 1, 2 ve 3 numaralı çözeltilerde sırası ile Alüminyum Potasyum Sülfat (Alum), Demir (II) Sülfat ve Tannik Asit mordanı ile pH 2'de boyama sonucu görselidir. Şekil 4'te belirtilen 4, 5, 6 numaralı boyamalar sırası ile Alüminyum Potasyum Sülfat (Alum), Demir (II) Sülfat ve Tannik Asit mordanı ile $\mathrm{pH}$ 4'te boyama sonrası görselidir. Şekil 4'da belirtilen 7, 8, 9 numaralı boyama çözeltileri sırası ile Alüminyum Potasyum Sülfat (Alum), Demir (II) Sülfat ve Tannik Asit mordanı ile pH 6'da boyama sonrası görselidir. Şekil 5 ve 6'da eş zamanlı mordanlama ve son mordanlama yöntemlerinin yukarıdabelirtilen sıra ile çözelti görselleri bulunmaktadır. Şekil 7' de yine $\mathrm{pH}$ 2, 4 ve 6 sirasında ama mordansız yapılan boyama sonrası çözelti görselleri verilmiştir. Burada üçer örnekler sırasıyla $\% 0.5, \% 1$ ve $\% 2$ boyama konsantrasyonları boyama sonu çözelti örnekleridir (Tablo 10 ve 14).

Tablo 1. \%0,5 TFP Boya ile Ön Mordanlama Prosesi, Boyama Öncesi ve Sonrası Absorbans Ölçümleri

\begin{tabular}{|c|c|c|c|c|}
\hline \multicolumn{5}{|c|}{ Ön Mordanlama Sonrası Absorbans Ölçümleri } \\
\hline Numune Adı & $\begin{array}{c}\text { Dalga Boyu } \\
\text { (nm) }\end{array}$ & $\begin{array}{c}\text { Boyama Öncesi } \\
\text { Absorbans }\end{array}$ & $\begin{array}{c}\text { Boyama Sonrası } \\
\text { Absorbans }\end{array}$ & $\begin{array}{l}\text { \% Boya } \\
\text { Çekimi }\end{array}$ \\
\hline \%0,5 TFP, \%Alum-pH:2 & 610 & 0,2738 & 0,0559 & 79,58 \\
\hline$\% 0,5$ TFP, $\% \mathrm{Fe}_{2} \mathrm{SO}_{4}-\mathrm{pH}: 2$ & 610 & 0,3031 & 0,0557 & 81,62 \\
\hline$\% 0,5$ TFP, \%Tannik Asit-pH:2 & 610 & 0,3101 & 0,0547 & 82,36 \\
\hline \%0,5 TFP, \%Alum-pH:4 & 610 & 0,3288 & 0,0598 & 81,81 \\
\hline$\% 0,5$ TFP, $\% \mathrm{Fe}_{2} \mathrm{SO}_{4}-\mathrm{pH}: 4$ & 610 & 0,3354 & 0,0595 & 82,26 \\
\hline$\% 0,5$ TFP \%Tannik Asit-pH:4 & 610 & 0,3388 & 0,0587 & 82,67 \\
\hline \%0, TFP \%Alum-pH:6 & 610 & 0,3328 & 0,0669 & 79,90 \\
\hline$\% 0,5$ TFP $\% \mathrm{Fe}_{2} \mathrm{SO}_{4}-\mathrm{pH}: 6$ & 610 & 0,3273 & 0,0705 & 78,46 \\
\hline$\% 0,5$ TFP $\%$ Tannik Asit-pH:6 & 610 & 0,3365 & 0,067 & 80,09 \\
\hline
\end{tabular}


Tablo 2. \%1 TFP Boya ile Ön Mordanlama Prosesi, Boyama Öncesi ve Sonrası Absorbans Ölçümleri

\begin{tabular}{|c|c|c|c|c|}
\hline \multicolumn{5}{|c|}{ Ön Mordanlama Sonrası Absorbans Ölçümleri } \\
\hline Numune Adı & $\begin{array}{c}\text { Dalga Boyu } \\
\text { (nm) }\end{array}$ & $\begin{array}{c}\text { Boyama Öncesi } \\
\text { Absorbans }\end{array}$ & $\begin{array}{c}\text { Boyama Sonrası } \\
\text { Absorbans }\end{array}$ & $\begin{array}{l}\text { \% Boya } \\
\text { Çekimi }\end{array}$ \\
\hline \%1 TFP, \%Alum-pH:2 & 610 & 0,5766 & 0,0575 & 90,03 \\
\hline$\% 1 \mathrm{TFP}, \% \mathrm{Fe}_{2} \mathrm{SO}_{4}-\mathrm{pH}: 2$ & 610 & 0,6016 & 0,0568 & 90,56 \\
\hline \%1 TFP, \%Tannik Asit-pH:2 & 610 & 0,5708 & 0,056 & 90,19 \\
\hline \%1 TFP \%Alum-pH:4 & 610 & 0,6018 & 0,0586 & 90,26 \\
\hline$\% 1 \mathrm{TFP} \% \mathrm{Fe}_{2} \mathrm{SO}_{4}-\mathrm{pH}: 4$ & 610 & 0,5957 & 0,0589 & 90,11 \\
\hline \%1 TFP \%Tannik Asit-pH:4 & 610 & 0,6032 & 0,0601 & 90,05 \\
\hline$\% 1$ TFP \%Alum-pH:6 & 610 & 0,4811 & 0,0621 & 87,09 \\
\hline$\% 1$ TFP, $\% \mathrm{Fe}_{2} \mathrm{SO}_{4}-\mathrm{pH}: 6$ & 610 & 0,553 & 0,0735 & 86,71 \\
\hline \%1 TFP, \%Tannik Asit-pH:6 & 610 & 0,5507 & 0,0772 & 85,98 \\
\hline
\end{tabular}

Tablo 3. \%2 TFP Boya ile Ön Mordanlama Prosesi, Boyama Öncesi ve Sonrası Absorbans Ölçümleri

\begin{tabular}{|c|c|c|c|c|}
\hline \multicolumn{5}{|c|}{ Eş Zamanlı Mordanlama Sonrası Absorbans Ölçümleri } \\
\hline Numune Adı & $\begin{array}{c}\text { Dalga Boyu } \\
(\mathbf{n m})\end{array}$ & $\begin{array}{c}\text { Boyama Öncesi } \\
\text { Absorbans }\end{array}$ & $\begin{array}{c}\text { Boyama Sonrası } \\
\text { Absorbans }\end{array}$ & $\begin{array}{l}\text { \% Boya } \\
\text { Çekimi }\end{array}$ \\
\hline$\% 2$ TFP, \%Alum-pH:2 & 610 & 1,0113 & 0,0637 & 93,70 \\
\hline$\% 2 \mathrm{TFP}, \%{ }_{0} \mathrm{Fe}_{2} \mathrm{SO}_{4}-\mathrm{pH}: 2$ & 610 & 1,0423 & 0,0635 & 93,91 \\
\hline \%2 TFP, \%Tannik Asit-pH:2 & 610 & 1,0482 & 0,065 & 93,80 \\
\hline$\% 2$, TFP, \%Alum-pH:4 & 610 & 1,1073 & 0,1164 & 89,49 \\
\hline$\% 2$ TFP, $\% \mathrm{Fe}_{2} \mathrm{SO}_{4}-\mathrm{pH}: 4$ & 610 & 1,0519 & 0,1089 & 89,65 \\
\hline \%2 TFP, \%Tannik Asit-pH:4 & 610 & 0,9128 & 0,0967 & 89,41 \\
\hline$\% 2$ TFP, \%Alum-pH:6 & 610 & 1,0431 & 0,2247 & 78,46 \\
\hline$\% 2$ TFP, $\% \mathrm{Fe}_{2} \mathrm{SO}_{4}-\mathrm{pH}: 6$ & 610 & 1,0781 & 0,2574 & 76,12 \\
\hline \%2 TFP, \% Tannik Asit-pH:6 & 610 & 1,0696 & 0,2776 & 74,05 \\
\hline
\end{tabular}

Tablo 4. \%0,5 TFP Boya ile Eş Zamanlı Mordanlama Prosesi, Boyama Öncesi ve Sonrası Absorbans Ölçümleri

\begin{tabular}{|c|c|c|c|c|}
\hline \multicolumn{5}{|c|}{ Eş Zamanlı Mordanlama Sonrası Absorbans Ölçümleri } \\
\hline Numune Adı & $\begin{array}{c}\text { Dalga Boyu } \\
(\mathrm{nm})\end{array}$ & $\begin{array}{c}\text { Boyama Öncesi } \\
\text { Absorbans }\end{array}$ & $\begin{array}{c}\text { Boyama Sonrasi } \\
\text { Absorbans }\end{array}$ & $\begin{array}{l}\text { \% Boya } \\
\text { Çekimi }\end{array}$ \\
\hline$\% 0,5$ TFP, $\%$ Alum-pH:2 & 610 & 0,2728 & 0,0674 & 75,29 \\
\hline$\% 0,5$ TFP, $\% \mathrm{Fe}_{2} \mathrm{SO}_{4}-\mathrm{pH}: 2$ & 610 & 0,2821 & 0,0691 & 75,50 \\
\hline$\% 0,5$ TFP, \%Tannik Asit-pH:2 & 610 & 0,2793 & 0,0670 & 76,01 \\
\hline$\% 0,5$ TFP, \%Alum-pH:4 & 610 & 0,2858 & 0,0684 & 76,07 \\
\hline$\% 0,5$ TFP, $\% \mathrm{Fe}_{2} \mathrm{SO}_{4}-\mathrm{pH}: 4$ & 610 & 0,2890 & 0,0678 & 76,54 \\
\hline$\% 0,5$ TFP $\%$ Tannik Asit-pH:4 & 610 & 0,2843 & 0,0677 & 76,19 \\
\hline \%0,5 TFP \%Alum-pH:6 & 610 & 0,2943 & 0,0717 & 75,64 \\
\hline$\% 0,5$ TFP $\% \mathrm{Fe}_{2} \mathrm{SO}_{4}-\mathrm{pH}: 6$ & 610 & 0,2873 & 0,0711 & 75,25 \\
\hline \%0,5 TFP \%Tannik Asit-pH:6 & 610 & 0,2963 & 0,0641 & 78,37 \\
\hline
\end{tabular}

Tablo 5. \%1 TFP Boya ile Eş Zamanlı Mordanlama Prosesi, Boyama Öncesi ve Sonrası Absorbans Ölçümleri

\begin{tabular}{|c|c|c|c|c|}
\hline \multicolumn{5}{|c|}{ Eş Zamanlı Mordanlama Sonrası Absorbans Ölçümleri } \\
\hline Numune Adı & $\begin{array}{c}\text { Dalga Boyu } \\
\text { (nm) }\end{array}$ & $\begin{array}{c}\text { Boyama Öncesi } \\
\text { Absorbans }\end{array}$ & $\begin{array}{c}\text { Boyama Sonrası } \\
\text { Absorbans }\end{array}$ & $\begin{array}{l}\text { \% Boya } \\
\text { Çekimi }\end{array}$ \\
\hline
\end{tabular}


European Journal of Science and Technology

\begin{tabular}{|c|c|c|c|c|}
\hline \%1 TFP, \%Alum-pH:2 & 610 & 0,5094 & 0,0603 & 88,16 \\
\hline$\% 1$ TFP, $\% \mathrm{Fe}_{2} \mathrm{SO}_{4}-\mathrm{pH}: 2$ & 610 & 0,4979 & 0,0592 & 88,11 \\
\hline$\% 1$ TFP, \%Tannik Asit-pH:2 & 610 & 0,5051 & 0,0571 & 88,69 \\
\hline$\% 1$ TFP \%Alum-pH:4 & 610 & 0,5153 & 0,0646 & 87,46 \\
\hline$\% 1$ TFP $\% \mathrm{Fe}_{2} \mathrm{SO}_{4}-\mathrm{pH}: 4$ & 610 & 0,5180 & 0,0621 & 88,01 \\
\hline$\% 1$ TFP \%Tannik Asit-pH:4 & 610 & 0,5108 & 0,0640 & 87,47 \\
\hline \%1 TFP \%Alum-pH:6 & 610 & 0,4166 & 0,0811 & 80,53 \\
\hline$\% 1 \mathrm{TFP}, \% \mathrm{Fe}_{2} \mathrm{SO}_{4}-\mathrm{pH}: 6$ & 610 & 0,4213 & 0,0815 & 80,66 \\
\hline \%1 TFP, \%Tannik Asit-pH:6 & 610 & 0,4171 & 0,0872 & 79,09 \\
\hline
\end{tabular}

Tablo 6. \%2 TFP Boya ile Eş Zamanlı Mordanlama Prosesi, Boyama Öncesi ve Sonrası Absorbans Ölçümleri

\begin{tabular}{|c|c|c|c|c|}
\hline \multicolumn{5}{|c|}{ Eş Zamanlı Mordanlama Sonrası Absorbans Ölçümleri } \\
\hline Numune Adı & $\begin{array}{c}\text { Dalga Boyu } \\
(\mathrm{nm})\end{array}$ & $\begin{array}{c}\text { Boyama Öncesi } \\
\text { Absorbans }\end{array}$ & $\begin{array}{c}\text { Boyama Sonrası } \\
\text { Absorbans }\end{array}$ & $\begin{array}{l}\text { \% Boya } \\
\text { Çekimi }\end{array}$ \\
\hline$\% 2$ TFP, \%Alum-pH:2 & 610 & 0,7302 & 0,0678 & 90,71 \\
\hline$\% 2$ TFP, $\% \mathrm{Fe}_{2} \mathrm{SO}_{4}-\mathrm{pH}: 2$ & 610 & 0,7092 & 0,0700 & 90,13 \\
\hline \%2 TFP, \%Tannik Asit-pH:2 & 610 & 0,7308 & 0,0686 & 90,61 \\
\hline$\% 2$, TFP, \%Alum-pH:4 & 610 & 0,7671 & 0,1094 & 85,74 \\
\hline$\% 2$ TFP, $\% \mathrm{Fe}_{2} \mathrm{SO}_{4}-\mathrm{pH}: 4$ & 610 & 0,7426 & 0,1208 & 83,73 \\
\hline \%2 TFP, \%Tannik Asit-pH:4 & 610 & 0,7659 & 0,1204 & 84,28 \\
\hline \%2 TFP, \%Alum-pH:6 & 610 & 0,7879 & 0,3129 & 60,29 \\
\hline$\% 2$ TFP, $\% \mathrm{Fe}_{2} \mathrm{SO}_{4}-\mathrm{pH}: 6$ & 610 & 0,7733 & 0,3207 & 58,53 \\
\hline \%2 TFP, \%Tannik Asit-pH:6 & 610 & 0,7288 & 0,3367 & 53,80 \\
\hline
\end{tabular}

Tablo 7. \%0,5 TFP Boya ile Son Mordanlama Prosesi, Boyama Öncesi ve Sonrası Absorbans Ölçümleri

\begin{tabular}{|c|c|c|c|c|c|c|}
\hline \multicolumn{7}{|c|}{ Son Mordanlama Sonrası Absorbans Ölçümleri } \\
\hline Numune Adı & $\begin{array}{l}\text { Dalga } \\
\text { Boyu } \\
(\mathrm{nm})\end{array}$ & $\begin{array}{c}\text { Boyama } \\
\text { Öncesi } \\
\text { Absorbans }\end{array}$ & $\begin{array}{c}\text { Boyama } \\
\text { Öncesi } \\
\text { Absorbans }\end{array}$ & $\begin{array}{l}\% \text { Boya } \\
\text { Çekimi }\end{array}$ & $\begin{array}{c}\text { Boyama } \\
\text { Sonrası } \\
\text { Absorbans }\end{array}$ & $\begin{array}{l}\% \text { Boya } \\
\text { Çekimi }\end{array}$ \\
\hline$\% 0,5$ TFP, \%Alum-pH:2 & 610 & 0,2564 & 0,0552 & 78,47 & 0,0560 & 78,16 \\
\hline$\% 0,5$ TFP, $\% \mathrm{Fe}_{2} \mathrm{SO}_{4}-\mathrm{pH}: 2$ & 610 & 0,2586 & 0,0550 & 78,73 & 0,0546 & 78,89 \\
\hline \%0,5 TFP, \%Tannik Asit-pH:2 & 610 & 0,2562 & 0,0535 & 79,12 & 0,0548 & 78,61 \\
\hline \%0,5 TFP, \%Alum-pH:4 & 610 & 0,2725 & 0,0574 & 78,94 & 0,0554 & 79,67 \\
\hline$\% 0,5$ TFP, $\% \mathrm{Fe}_{2} \mathrm{SO}_{4}-\mathrm{pH}: 4$ & 610 & 0,2682 & 0,0580 & 78,37 & 0,0549 & 79,53 \\
\hline$\% 0,5$ TFP \%Tannik Asit-pH:4 & 610 & 0,2659 & 0,0579 & 78,22 & 0,0557 & 79,05 \\
\hline$\% 0$, TFP \%Alum-pH:6 & 610 & 0,2747 & 0,1132 & 58,79 & 0,0601 & 78,16 \\
\hline$\% 0,5$ TFP, $\% \mathrm{Fe}_{2} \mathrm{SO}_{4}-\mathrm{pH}: 6$ & 610 & 0,2717 & 0,1188 & 56,28 & 0,0596 & 78,06 \\
\hline \%0,5 TFP, \%Tannik Asit-pH:6 & 610 & 0,2693 & 0,1275 & 52,66 & 0,0625 & 76,79 \\
\hline
\end{tabular}

Tablo 8. \%1 TFP Boya ile Son Mordanlama Prosesi, Boyama Öncesi ve Sonrası Absorbans Ölçümleri

\begin{tabular}{|c|c|c|c|c|c|c|}
\hline \multicolumn{7}{|c|}{ Son Mordanlama Sonrası Absorbans Ölçümleri } \\
\hline Numune Adı & $\begin{array}{l}\text { Dalga } \\
\text { Boyu } \\
(\mathrm{nm})\end{array}$ & $\begin{array}{c}\text { Boyama } \\
\text { Öncesi } \\
\text { Absorbans }\end{array}$ & $\begin{array}{c}\text { Boyama } \\
\text { Öncesi } 2 \\
\text { Absorbans }\end{array}$ & $\begin{array}{l}\% \text { Boya } \\
\text { Çekimi }\end{array}$ & $\begin{array}{c}\text { Boyama } \\
\text { Sonrası } \\
\text { Absorbans }\end{array}$ & $\begin{array}{l}\% \text { Boya } \\
\text { Çekimi }\end{array}$ \\
\hline$\% 1$ TFP, \%Alum-pH:2 & 610 & 0,4671 & 0,0632 & 86,47 & 0,0551 & 88,20 \\
\hline$\% 1 \mathrm{TFP}, \% \mathrm{Fe}_{2} \mathrm{SO}_{4}-\mathrm{pH}: 2$ & 610 & 0,4600 & 0,0608 & 86,78 & 0,0554 & 87,96 \\
\hline \%1 TFP, \%Tannik Asit-pH:2 & 610 & 0,4709 & 0,0620 & 86,83 & 0,0553 & 88,26 \\
\hline
\end{tabular}




\begin{tabular}{|c|c|c|c|c|c|c|}
\hline$\% 1$ TFP \%Alum-pH:4 & 610 & 0,4969 & 0,1144 & 76,98 & 0,0581 & 88,31 \\
\hline$\% 1$ TFP $\% \mathrm{Fe}_{2} \mathrm{SO}_{4}-\mathrm{pH}: 4$ & 610 & 0,5034 & 0,1223 & 75,71 & 0,0572 & 88,64 \\
\hline \%1 TFP \%Tannik Asit-pH:4 & 610 & 0,5032 & 0,1217 & 75,81 & 0,0581 & 88,45 \\
\hline \%1 TFP \%Alum-pH:6 & 610 & 0,4733 & 0,2549 & 46,14 & 0,0738 & 84,41 \\
\hline$\% 1$ TFP, $\% \mathrm{Fe}_{2} \mathrm{SO}_{4}$-pH:6 & 610 & 0,4914 & 0,3123 & 36,45 & 0,0789 & 83,94 \\
\hline \%1 TFP, \%Tannik Asit-pH:6 & 610 & 0,4854 & 0,3165 & 34,80 & 0,0863 & 82,22 \\
\hline
\end{tabular}

Tablo 9. \%2 TFP Boya ile Son Mordanlama Prosesi, Boyama Öncesi ve Sonrast Absorbans

\begin{tabular}{|c|c|c|c|c|c|c|}
\hline \multicolumn{7}{|c|}{ Son Mordanlama Sonrası Absorbans Ölçümleri } \\
\hline Numune Adı & $\begin{array}{l}\text { Dalga } \\
\text { Boyu } \\
(\mathbf{n m})\end{array}$ & $\begin{array}{c}\text { Boyama } \\
\text { Öncesi } \\
\text { Absorbans }\end{array}$ & $\begin{array}{c}\text { Boyama } \\
\text { Öncesi } 2 \\
\text { Absorbans }\end{array}$ & $\begin{array}{l}\text { \% Boya } \\
\text { Çekimi }\end{array}$ & $\begin{array}{c}\text { Boyama } \\
\text { Sonrası } \\
\text { Absorbans }\end{array}$ & $\begin{array}{l}\% \text { Boya } \\
\text { Çekimi }\end{array}$ \\
\hline$\% 2$ TFP, \%Alum-pH:2 & 610 & 0,8641 & 0,1321 & 84,71 & 0,0685 & 92,07 \\
\hline$\% 2 \mathrm{TFP}, \% \mathrm{Fe}_{2} \mathrm{SO}_{4}-\mathrm{pH}: 2$ & 610 & 0,7908 & 0,1789 & 77,38 & 0,0668 & 91,55 \\
\hline \%2 TFP, \%Tannik Asit-pH:2 & 610 & 0,8314 & 0,1595 & 80,82 & 0,0730 & 91,22 \\
\hline \%2, TFP, \%Alum-pH:4 & 610 & 0,8337 & 0,3743 & 55,10 & 0,1240 & 85,13 \\
\hline$\% 2$ TFP, $\% \mathrm{Fe}_{2} \mathrm{SO}_{4}-\mathrm{pH}: 4$ & 610 & 0,7541 & 0,4448 & 41,02 & 0,1460 & 80,64 \\
\hline \%2 TFP, \%Tannik Asit-pH:4 & 610 & 0,8818 & 0,4750 & 46,13 & 0,1219 & 86,18 \\
\hline \%2 TFP, \%Alum-pH:6 & 610 & 0,8822 & 0,7608 & 13,76 & 0,3347 & 62,06 \\
\hline$\% 2$ TFP, $\% \mathrm{Fe}_{2} \mathrm{SO}_{4}-\mathrm{pH}: 6$ & 610 & 0,9095 & 0,7615 & 16,27 & 0,3432 & 62,26 \\
\hline \%2 TFP, \%Tannik Asit-pH:6 & 610 & 0,8992 & 0,7401 & 17,69 & 0,3336 & 62,90 \\
\hline
\end{tabular}

Tablo 10. Mordansız Boyama Öncesi ve Sonrası Absorbans Ölçümleri

\begin{tabular}{|l|c|c|c|c|}
\hline \multicolumn{5}{|c|}{ Mordansız Boyama Sonrası Absorbans Ölçümleri } \\
\hline Numune Adı & $\begin{array}{c}\text { Dalga Boyu } \\
(\mathbf{n m})\end{array}$ & $\begin{array}{c}\text { Boyama Öncesi } \\
\text { Absorbans }\end{array}$ & $\begin{array}{c}\text { Boyama Sonrası } \\
\text { Absorbans }\end{array}$ & $\begin{array}{c}\text { \% Boya } \\
\text { Çekimi }\end{array}$ \\
\hline \%0,5TFP -pH:2 & 610 & 0,2454 & 0,0493 & 79,91 \\
\hline \%0,5 TFP -pH:4 & 610 & 0,2604 & 0,0488 & 81,26 \\
\hline \%0,5 TFP -pH:6 & 610 & 0,2611 & 0,0508 & 80,54 \\
\hline \%1 TFP -pH:2 & 610 & 0,4711 & 0,0487 & 89,66 \\
\hline \%1 TFP -pH:4 & 610 & 0,4937 & 0,0502 & 89,83 \\
\hline \%1 TFP -pH:6 & 610 & 0,4701 & 0,0653 & 86,11 \\
\hline \%2 TFP -pH:2 & 610 & 0,8934 & 0,0711 & 92,04 \\
\hline \%2 TFP -pH:4 & 610 & 0,8715 & 0,1043 & 88,03 \\
\hline \%2 TFP -pH:6 & 610 & 0,9237 & 0,2250 & 75,64 \\
\hline
\end{tabular}

Tablo 11. \%0,5 TFP ile Boyanan Kumaşların K/S Değerleri

\begin{tabular}{|c|c|c|c|}
\hline Numune Adı & $\begin{array}{c}\text { Ön Mordanlama } \\
\text { Sonrası K/S }\end{array}$ & $\begin{array}{c}\text { Eş Zamanlı Mordanlama } \\
\text { Sonrası K/S }\end{array}$ & $\begin{array}{c}\text { Son Mordanlama Sonrası } \\
\mathrm{K} / \mathrm{S}\end{array}$ \\
\hline$\% 0,5$ TFP, \%Alum-pH:2 & 0,7812 & 0,8587 & 0,8599 \\
\hline$\% 0,5$ TFP, $\% \mathrm{Fe}_{2} \mathrm{SO}_{4}-\mathrm{pH}: 2$ & 0,9125 & 0,8260 & 0,9101 \\
\hline$\% 0,5$ TFP, \%Tannik Asit-pH:2 & 0,8497 & 0,8211 & 0,8969 \\
\hline \%0,5 TFP, \%Alum-pH:4 & 0,7240 & 0,7029 & 0,7255 \\
\hline$\% 0,5$ TFP, $\% \mathrm{Fe}_{2} \mathrm{SO}_{4}-\mathrm{pH}: 4$ & 0,7360 & 0,7481 & 0,7531 \\
\hline$\% 0,5$ TFP \%Tannik Asit-pH:4 & 0,8095 & 0,7345 & 0,7938 \\
\hline$\% 0$, TFP \%Alum-pH:6 & 0,6792 & 0,6556 & 0,6481 \\
\hline
\end{tabular}


European Journal of Science and Technology

\begin{tabular}{|l|c|c|c|}
\hline$\% 0,5$ TFP, $\% \mathrm{Fe}_{2} \mathrm{SO}_{4}-\mathrm{pH}: 6$ & 0,6605 & 0,6436 & 0,68171 \\
\hline$\% 0,5$ TFP, $\%$ Tannik Asit-pH:6 & 0,6883 & 0,6641 & 0,6644 \\
\hline
\end{tabular}

Tablo 12. \%1 TFP ile Boyanan Kumaşların K/S Değerleri

\begin{tabular}{|l|c|c|c|}
\hline \multicolumn{1}{|c|}{ Numune Adı } & $\begin{array}{c}\text { Ön Mordanlama } \\
\text { Sonrası K/S }\end{array}$ & $\begin{array}{c}\text { Eş Zamanlı Mordanlama } \\
\text { Sonrası K/S }\end{array}$ & $\begin{array}{c}\text { Son Mordanlama Sonrası } \\
\text { K/S }\end{array}$ \\
\hline \%1 TFP, \%Alum-pH:2 & 1,4355 & 1,3993 & 1,3067 \\
\hline \%1 TFP, \%Fe $\mathrm{SO}_{4}$-pH:2 & 1,4259 & 1,3070 & 1,3598 \\
\hline \%1 TFP, \%Tannik Asit-pH:2 & 1,4125 & 1,2634 & 1,3463 \\
\hline \%1 TFP \%Alum-pH:4 & 1,2989 & 1,2069 & 1,204 \\
\hline \%1 TFP \%Fe $\mathrm{SO}_{4}$-pH:4 & 1,1919 & 1,2385 & 1,2157 \\
\hline \%1 TFP \%Tannik Asit-pH:4 & 1,2077 & 1,2532 & 1,0597 \\
\hline \%1 TFP \%Alum-pH:6 & 1,0803 & 1,0629 & 1,0708 \\
\hline \%1 TFP, \%Fe $\mathrm{SO}_{4}$-pH:6 & 1,0713 & 1,0769 & 1,0711 \\
\hline \%1 TFP, \%Tannik Asit-pH:6 & 1,0945 & 1,0858 & \\
\hline
\end{tabular}

Tablo 13. \%2 TFP ile Boyanan Kumaşların K/S Değerleri

\begin{tabular}{|c|c|c|c|}
\hline Numune Adı & $\begin{array}{c}\text { Ön Mordanlama } \\
\text { Sonrası K/S }\end{array}$ & $\begin{array}{c}\text { Eş Zamanlı Mordanlama } \\
\text { Sonrası K/S }\end{array}$ & $\begin{array}{c}\text { Son Mordanlama Sonrası } \\
\text { K/S }\end{array}$ \\
\hline \%2 TFP, \%Alum-pH:2 & 2,3102 & 2,2268 & 2,2232 \\
\hline$\% 2$ TFP, $\% \mathrm{Fe}_{2} \mathrm{SO}_{4}-\mathrm{pH}: 2$ & 2,3192 & 2,2522 & 2,1596 \\
\hline \%2 TFP, \%Tannik Asit-pH:2 & 2,3025 & 2,2009 & 2,228 \\
\hline \%2, TFP, \%Alum-pH:4 & 2,0134 & 1,8950 & 1,9242 \\
\hline$\% 2$ TFP, $\% \mathrm{Fe}_{2} \mathrm{SO}_{4}-\mathrm{pH}: 4$ & 1,9775 & 1,9639 & 1,9414 \\
\hline \%2 TFP, \%Tannik Asit-pH:4 & 1,9418 & 1,9307 & 1,9245 \\
\hline \%2 TFP, \%Alum-pH:6 & 1,5777 & 1,4664 & 1,4922 \\
\hline$\% 2$ TFP, $\% \mathrm{Fe}_{2} \mathrm{SO}_{4}$-pH:6 & 1,5730 & 1,4457 & 1,4561 \\
\hline \%2 TFP, \%Tannik Asit-pH:6 & 1,5871 & 1,4424 & 1,5261 \\
\hline
\end{tabular}

Tablo 14. Mordansız Boyama Sonrası Kumaşların K/S değerleri

\begin{tabular}{|l|c|}
\hline \multicolumn{1}{|c|}{ Numune Adı } & K/S Değerleri \\
\hline$\% 0,5$ TFP-pH:2 & 0,7867 \\
\hline$\% 0,5$ TFP-pH:4 & 0,7636 \\
\hline$\% 0,5$ TFP-pH:6 & 0,6991 \\
\hline$\% 1$ TFP - pH:2 & 1,3441 \\
\hline$\% 1$ TFP -pH:4 & 1,2801 \\
\hline$\% 1$ TFP -pH:6 & 1,0646 \\
\hline$\% 2$ TFP -pH:2 & 2,3269 \\
\hline$\% 2$ TFP -pH:4 & 1,9636 \\
\hline$\% 2$ TFP -pH:6 & 1,6433 \\
\hline
\end{tabular}

\subsection{Tartışma}

Trifloropirimidin (TFP) reaktif boyarmaddesi ile nylon kumaşın üç farklı proses, mordan ve $\mathrm{pH}$ aralığında boyama sonuçları sunulmuştur. Boyama öncesinde $\mathrm{pH}$ ayarlanması için Mcllvaine tampon çözeltisinden yararlanılmıştır. Boyama öncesi çözeltilerin $\mathrm{pH}$ değerleri ölçülerek, mordan ilavesi yapılıp boyama sonrasında da $\mathrm{pH}$ ölçümü yapılmıştır. Yapılan ölçü̈ler

sonrasında üç proseste de mordan kullanımına bağlı olarak sonuçları etkileyecek kadar yüksek $\mathrm{pH}$ değişimi gözlenmemiştir.

TFP reaktif boyarmaddesi kullanarak yapılan boyamalar sonrasinda \%0,5 boyarmadde konsantrasyonunda boyama sonuçlarının görselleri paylaşılmıştır. Şekil 4 'te ön mordanlama sonrası boyama görsellerine bakııldığında $\mathrm{pH} 6$ ile yapılan boyama sonrası, çözeltide kalan absorbe olmamış boyarmadde olduğu görülmektedir. Şekil 5'te $\% 0,5$ boyarmadde ile yapılan boyama görsellerine bakıldığında $\mathrm{pH} 2$ ve $\mathrm{pH} 4$ 'te boyarmadde çekiminin 
olduğu, pH 6'da ise boyarmadde çekiminin ön mordanlama prosesine göre daha iyi olduğu gözlenmiştir. Şekil 6'da \%0,5 boyarmadde konsantrasyonu ile son mordanlama prosesinde boyama yapılmıştır. Boyama sonrası çözeltilere bakıldığında $\mathrm{pH}$ 6'da yapılan boyamalarda, boyarmadde çekimlerinin yeterli olmadığı görülmüştür. Mordansız boyama sonuçlarına bakıldığında $\% 0,5, \% 1$ ve $\% 2$ boyama oranlarında yine $\mathrm{pH} 6$ 'da boyarmadde çekiminin yeterli olmadığı gözlenmiştir ( Şekil 7). Şekil 4-6' da \%0.5 boyama konsantrasyonu için verilen görsellere benzer şekilde $\% 1$ ve $\% 2$ boyama konsantrasyonları için sonuçlar elde edilmiştir.

Boyama öncesi ve sonrası absorbans değerleri incelendiğinde $\% 0,5$ 'lik boyarmadde ile boyama sonrasında $\mathrm{pH} 2$ ve 4 'te ön mordanlama prosesi ile yapilan boyamalarda, boyarmadde çekiminin fazla olduğu görülmektedir (Tablo 1, Tablo 4, Tablo 7). Boyama sonrası absorbans değerleri incelendiğinde \%1'lik boyarmadde konsantrasyonunda yapılan boyamalarda ön mordanlama ile $\mathrm{pH} 2$ ve 4'te yapılan boyamaların daha yüksek boyarmadde çekimi elde edildiği görülmüştür (Tablo 2, Tablo 5, Tablo 8). \%2'lik boyarmadde konsantrasyonunda yapilan boyamalarda ön mordanlama ile $\mathrm{pH} 2$ 'de yapilan boyamaların absorbans değerlerinin daha yüksek olduğu gözlenmiştir (Tablo 3, Tablo 6, Tablo 9).

Boyama işlemi tamamlanan nylon kumaşların renk ölçümleri reflektans spektrofotometresinde ölçülmüştür. $\mathrm{Bu}$ ölçümler sonucunda $\mathrm{K} / \mathrm{S}$ renk derinliği değerleri elde edilmiştir. K/S değerleri arttıkça görsel renk koyuluğu ve renk derinliğ artmaktadır. Yapılan ölçümler sonrasında \%0,5'lik boyama ile ön mordanlama prosesinde daha yüksek renk derinliği $(\mathrm{K} / \mathrm{S})$ elde edilmiştir (Tablo 11). \%1'lik boyama yapılan kumaşlarda K/S değerlerine bakıldığında ön mordanlama prosesinde daha yüksek renk derinliği elde edildiği gözlenmiştir (Tablo 12). \%2'lik boyarmadde oranında yapılan boyamalarda, kumaşların renk derinliği incelendiğinde ön mordanlama ve eş zamanlı mordanlama prosesi sonrasında kumaşların renk derinliklerinin birbirine yakın olduğu gözlenmiştir (Tablo 13).

TFP reaktif grubuna sahip boyarmadde ile mordansız yapılan boyamalar Tablo 10'da verilmiştir. Mordansız ve mordanlı boyamalarda, boyarmadde yüzdeleri dikkate alındığında mordanlama işleminin boyarmadde çekimini arttırdığı gözlenmiştir. Geleneksel literatürde verilen üç mordanlama yöntemi arasında son mordanlama öne çıkıyor olmasına rağmen bu deneysel çalışmada ön mordanlama ve eş zamanlı mordanlama ile daha iyi renklendirmeler elde edilmiştir.

\section{Sonuç}

Uygulanan üç farklı proses ile nylon kumaşların trifloropirimidin fonksiyonel grubuna sahip mavi reaktif boyarmadde ile boyanması incelenmiştir. Üç farklı $\mathrm{pH}$, proses ve mordan varlığında yapılan çalışmada, mordan kullanımının boyarmadde çekimini arttırdığı gözlenmiştir. Boyama yapılan $\mathrm{pH}$ aralıklarına bakıldığında, $\mathrm{pH}$ 6'da yapılan boyama sonuçlarında iyi bir fiksasyon gözlenememiştir. Ayrıca kumaşların K/S değerleri dikkate alındığında $\mathrm{pH} 6$ ile yapılan boyamalarda yeterli renk derinliği sağlanamamıştır. En iyi boyama sonuçları genel olarak pH 2 ve 4 'te ve Alüminyum Potasyum Sülfat mordanının kullanımında elde edilmiştir. Diğer $\mathrm{pH}$ değerleri ile karşılaştırıldığında $\mathrm{pH} 4$ 'te elde edilen daha iyi renk derinliği (Renk Kuvveti) değerleri Burkinshaw ve Ganghi ([3] - [5]), Soleimani-Gorgani ve Taylor ([8] - [10]) ve Burkinshaw ve ark. [11] çalışmalarında verilen deneysel sonuçlarla uyumludur. e-ISSN: 2148-2683
Bununla beraber literatürdeki çalışmalardan farklı olarak uygulanan $\mathrm{pH}$ ve uygulanan yüzde boyarmadde miktarına bağlı olarak fiksasyon değerlerinin geleneksel uygulamalarda elde edilen sonuçlardan farklı olduğu saptanmıştır. Mordan varlığında daha yüksek boyarmadde konsantrasyonunda daha yüksek fiksasyon eldesi yeni bir sonuçtur. Özellikle mordan olarak Tannik Asit harici mordanların kullanılması yeni bir çalışma örneğidir ve yapılan çalışmalar burada verilen deneysel çalışma şartları altında Potasyum Alüminyum Sülfat (Alum) kullanımının daha iyi renk derinliği verebileceğini göstermiştir. Boyama literatüründe geleneksel mordanlama yöntemleri içinde en iyi sonuçların son mordanlama ile elde edilmekte olduğu bilgisine rağmen, yapılan bu deneysel çalışma için en iyi renklendirme değerleri ön mordanlama ve eş zamanlı mordanlamada elde edilmiştir. Tüm sonuçlara bakıldığında nylonun reaktif boyarmaddeler ile boyanmasında yeni yöntemlerin gelişmesi ile yüksek boyarmadde çekimi sağlaması, farklı uygulamaların tekstil sektöründe kullanılmasında yol açacaktır. Bu bulgulara göre nylon kumaşların TFP reaktif boyarmadde ile boyanmasında en iyi boyama değerleri Potasyum Alüminyum Sülfat (Alum) mordanı kullanımı ile pH 2 ve 4'te ön mordanlama ve eş zamanlı mordanlama ile elde edilebilir.

\section{Teșekkür}

$\mathrm{Bu}$ çalışma Bursa Uludağ Üniversitesi Bilimsel Araştırma Projeleri Koordinasyon Birimi tarafindan desteklenmiştir. (Proje No: FYL-2021-332).

\section{Kaynakça}

Burkinshaw, S.M. (1995). 2. Nylon. In Chemical Principles of Synthetic Fibre dyeing. pp. 77-80. Glasgow: Blackie Academic \& Professional.

Burkinshaw S.M., Ganghi K. (1996). The Dyeing of Conventional Decitex and Microfibre Nylon 6,6 with Reactive Dyes-I. Chlorodifluoropyrimidinyl Dyes. Dyes and Pigments, 32 (2), 101-127.

Burkinshaw S.M., Ganghi K. (1997a). The Dyeing of Conventional and and Microfibre Nylon 6,6 with Reactive Dyes. Part 2. $\alpha$-Bromoacrylamido Dyes. Dyes and Pigments, 33 (4), 259-280.

Burkinshaw S.M., Ganghi K. (1997b). The Dyeing of Conventional and and Microfibre Nylon 6,6 with Reactive Dyes-3. Vinyl Sulphone and Chlortriazine Dyes. Dyes and Pigments, 34 (3), 243-253.

Burkinshaw S.M., Son Y-A, Bide M.J. (2001). The Application of Heterobifunctional Reactive Dyes to Nylon 6,6: Process Modifications to Achieve High Efficiencies. Dyes and Pigments, 48, 245-251.

El-Gabry L.K., El-Zawary M.M. (2008). Effect of Tannic Acid on the Dyeing Process of Nylon 6 Fabric with a Cationic Dye. Research Journal of Textile and Apparel, 12 (4), 21-30.

Lewis D.M., MacDangall W.C. (1998). Dyeing Nylon 6,6 with Vinylsulfone reactive Dyes. Textile Chemist and Colorist, 30 (5), 31-35.

Rys P., Zollinger H. (1989). Reactive Dye-Fibre Systems. In The Theory of Coloration of Textiles. 2nd Edition, ed. A. Johnson, pp. 428-431. Bradford: Society of Dyers and Colourists.

Soleimani-Gorgani A., Taylor J.A. (2006a). Dyeing of Nylon with Reactive Dyes. Part 1. The Effect of Changes in Dye Structure on the Dyeing of Nylon with Reactive Dyes. Dyes and Pigments, 68, 109-117. 
Soleimani-Gorgani A., Taylor J.A. (2006b). Dyeing of Nylon with Reactive Dyes. Part 2. The Effect of Changes in Level of Dye Sulphonation on the Dyeing of Nylon with Reactive Dyes. Dyes and Pigments, 68, 119-127.

Soleimani-Gorgani A., Taylor J.A. (2008). Dyeing of Nylon with Reactive Dyes. Part 2. Cationic Reactive Dyes for Nylon. Dyes and Pigments, 76, 610-623.

Sumithra M., Arasi D. (2014). A Novel Method of Dyeing Nylon 6,6 with Cold Brand Reactive Dyes and Assessment of its Fastness Properties. Journal of Textile Science and Engineering, S2:002, doi:10.4172/2165-8064.S2-002. 